Revista lus et Praxis, Año 22, № 2, 2016, pp. 227 - 252

ISSN 0717 - 2877

Universidad de Talca - Facultad de Ciencias Jurídicas y Sociales

La extensión de los ajustes razonables en el derecho de las personas

en situación de discapacidad de acuerdo al enfoque social de derechos humanos

Christian Finsterbusch Romero

Trabajo recibido el 4 de junio y aprobado el 22 de noviembre de 2015

\title{
La extensión de los ajustes razonables en el derecho de las personas en situación de discapacidad de acuerdo al enfoque social de derechos humanos
}

\author{
THE EXTENSION OF REASONABLE ACCOMMODATIONS IN THE RIGHT OF PERSONS \\ WITH DISABILITIES ACCORDING TO THE HUMAN RIGHTS SOCIAL APPROACH
}

\section{Christian Finsterbusch Romero*}

\begin{abstract}
RESUMEN
La Convención de Naciones Unidas sobre los Derechos de las Personas con Discapacidad, aparte de instaurar el nuevo paradigma "social de derechos humanos", codificó la obligatoriedad de realizar ajustes razonables, consistentes en modificaciones a situaciones concretas cuando una norma o política, sin ser en su origen discriminatoria, aplicada a una situación específica en el cual el destinatario de la misma es una persona en situación de discapacidad deviene injusta y contraria al principio de igualdad material. El texto concluye que los ajustes razonables y la carga indebida (como límite al primero) son conceptos complejos que se encuentran en la actualidad en pleno desarrollo jurisprudencial, debiendo analizarse en cada caso concreto sus propias particularidades para determinar su alcance.
\end{abstract}

\section{ABSTRACT}

The UN Convention on the Rights of Persons with Disabilities, apart from establishing a new "social human rights" paradigm, codified the obligation to make reasonable accommodations. It consists in changes to a specific situation, where a rule or policy without being in its origen discriminatory applied to a specific situation, where the addressee of it is a person with disability, becoming unjust and contrary to the principle of material equality. The text concludes that reasonable adjustments and undue burden (as the limit of the first) are complex concepts that are currently in jurisprudential development, becoming necessary to analyze each case and its characteristics to determine their scope.

\section{Palabras clave}

Ajustes razonables, Personas en situación de discapacidad, Carga indebida, Derecho internacional de los derechos humanos, Igualdad material

\section{KEYWORDS}

Reasonable accommodations, Persons with disabilities, Undue burden, International human rights law, Material equality

\footnotetext{
* Jefe Subdepto. Derecho y Discapacidad del Servicio Nacional de la Discapacidad de Chile. Profesor Posgrado en Derecho y Discapacidad. Máster II (Universidad Panthéon-Sorbonne). Correo electrónico: cfinsterbuschromero@gmail.com.
} 


\section{Introducción}

El Derecho es en principio la expresión de una voluntad compartida que se revela muchas veces como una relación de fuerzas, pero que tiene siempre como objetivo la manifestación de un ideal. Éste es el caso de la obligación de realización de ajustes razonables, construcción jurídica que se encuentra al servicio de la igualdad. En efecto, los ajustes razonables hacen un Ilamado a la imaginación conceptual, en donde la idea de un tratamiento diferenciado se vuelve necesaria en pro de exigencias de una igualdad material o efectiva. En este sentido, corresponde a una construcción intelectual que busca evitar la discriminación indirecta.

El ajuste razonable hace un Ilamado, asimismo, a la imaginación práctica, porque, una vez que la idea de un trato diferenciado y la realización de acciones positivas son admitidas a los efectos de alcanzar la plena igualdad de todas las personas en una sociedad, será necesario con posterioridad concretar la acción tendiente a materializar la igualdad, la que se apoya en una concepción de justicia social distributiva desde una perspectiva de ciudadanía incluyente. Se basa en un modelo intercultural concreto, que exige compartir los valores éticojurídicos cívicos, suponiendo el respeto del individuo tal como él es, tomando en cuenta la realización de esa acción en un contexto social.

El ajuste se inscribe en el cuadro de un derecho a la igualdad que presenta un carácter fundamentalmente reivindicatorio, buscando reposicionar una situación en un orden preestablecido. En este contexto son los particulares y las administraciones públicas los que deben gestionar la diversidad, tanto por la vía de la legislación con posibles excepciones previstas en las leyes como a través de ajustes razonables.

En el presente artículo se indaga acerca del concepto de ajustes razonables, como técnica jurídica en la resolución de conflictos, el nacimiento de los mismos, el tratamiento a la luz de la Convención de Naciones Unidas sobre los Derechos de las Personas con Discapacidad, sus características, la carga indebida o excesiva como límite al mismo y su evolución jurisprudencial, que ha ido construyendo criterios objetivos, tanto para la determinación del ajuste como para su límite en casos concretos.

\section{Los ajustes razonables}

\subsection{Antecedentes}

La Convención sobre los Derechos de las Personas con Discapacidad ${ }^{1}$ (en adelante CPCD/ONU), aprobada el 13 de diciembre de 2006 por la Asamblea

1 Convención sobre los Derechos de las Personas con Discapacidad de Naciones Unidas (2006). 
General de Naciones Unidas, produjo un cambio del paradigma respecto del enfoque existente en materia de discapacidad, pasando de uno eminentemente asistencialista $^{2}$ (existente hasta esta época) a otro social de derechos humanos, trasladando de esta manera el foco de la discapacidad desde la persona a las barreras sociales que impiden la inclusión de ésta en la sociedad.

En efecto, la discapacidad en sí misma, considerada en su desarrollo histórico, ha sido objeto de diferentes tratamientos, resultando de la sucesión de varios enfoques; sin embargo, el cambio más trascendente y revolucionario se produjo cuando se optó por transitar desde aquel que consideraba a una persona en situación de discapacidad como un sujeto meramente receptor de asistencia hacia uno que la consideraba sujeto de derechos, en donde el foco de la discapacidad dejó de centrarse en la persona, trasladándose a las barreras existentes en la sociedad que impiden a ésta poder incluirse en la misma en igualdad de condiciones ${ }^{3}$.

De acuerdo a Oliver "... el modo de concebir la discapacidad condiciona la respuesta que la sociedad ofrece a la misma" significado a los objetos que nos rodean determina que nuestro comportamiento a los mismos esté orientado en torno a aquel significado. De este modo, la aceptación del modelo social de derechos humanos tiene como consecuencia que la sociedad debe acomodar sus estructuras económicas y políticas, respetando la dignidad de quienes son diferentes ${ }^{5}$.

Como consecuencia de lo anterior, son los poderes públicos y los actores privados los Ilamados a asumir su responsabilidad en la modificación o eliminación de todas aquellas barreras que limitan a las personas en situación de discapacidad (en adelante PesD). Asimismo, como seres humanos iguales en dignidad, éstas no pueden ser tratadas como meros objetos de caridad, sino como sujetos, como un fin en sí mismo. Lo anterior tomando en cuenta que la CDPC/ONU dispone la obligatoriedad de adaptación de las normas existentes por los Estados Partes en conformidad a los criterios establecidos en este nuevo enfoque ${ }^{6}$.

No obstante lo anterior, existen situaciones en las cuales, a pesar de haber los Estados Partes realizado adaptaciones en conformidad al enfoque de derechos en su implementación interna, éstas no alcanzan para cumplir con los mandatos de la Convención, ni en la forma ni en el fondo. En efecto, existen situaciones que,

2 Pfeiffer (2002), pp. 3-23.

3 QUinn (2009), p. 3.

4 Citado por Biel (2009), p.11.

5 Biel (2009), p. 11.

${ }^{6}$ Convención Internacional de Naciones Unidas sobre los Derechos de las personas con Discapacidad (2006), art. $4^{\circ}$. 
por las particulares características de una PesD al enfrentar una situación en donde existe una barrera y aún cuando la norma, política, acción, procedimiento, en general no presenta carácter de discriminatoria, la persona igualmente no puede alcanzar la inclusión en la sociedad, por lo que la barrera no alcanzó a removerse.

Ante esta situación, la Convención mandata la realización de "ajustes razonables" con el objeto de alcanzar la igualdad material en el caso concreto, superando la barrera particular existente, materia objeto del presente estudio.

\subsection{Los ajustes razonables adecuados al cambio de paradigma}

La CPCD/ONU no sólo incorporó el nuevo cambio de paradigma en materia de discapacidad, haciendo suya la evolución doctrinaria en este sentido, sino que además incorporó un sistema innovador de resolución de problemas prácticos, ante la existencia de vulneraciones a los derechos de las PesD en razón de discapacidad, conocida como la técnica jurídica de los acomodos o ajustes razonables o necesarios, o simplemente, para los efectos de este artículo, "ajustes razonables".

La técnica anterior ya existía antes de la adopción de la Convención, siendo aplicada a la solución de conflictos suscitados en materias, hasta ese momento, fundamentalmente religiosas y de discriminación en países como Estados Unidos y Canadá 7 . Lo trascendente fue que hasta la fecha de adopción de la Convención ningún instrumento internacional de derechos humanos del sistema universal de Naciones Unidas ni de carácter regional la contemplaba.

A través de ésta se busca resolver, por parte de la autoridad (pública o judicial), en forma práctica situaciones donde al ser aplicada una ley, norma, política o procedimiento, formulada de un modo aparentemente neutro, en ciertas situaciones, en casos concretos deviene objetivamente injusta, por lo que la autoridad intenta darle la solución más justa posible, preservando el principio de igualdad material o efectiva. De esta manera, al no realizar diferencias que pudiesen ser catalogadas como arbitrarias, se resguarda el actuar en Derecho ${ }^{8}$. Ésta busca que los Estados empleen y desarrollen los mecanismos más acordes con su realidad sociocultural y económica adaptando prácticas, ambientes, reglas generales, etc., a objeto de suplir las diferencias existentes entre las personas para asegurarles una igualdad de oportunidades.

Se ha entendido que los ajustes constituyen una protección de segundo grado, que se activa cuando los principios destinados a las PesD no han podido

7 RAMBAud (2013).

8 Véase LaWson (2008). 
garantizar los derechos de éstas, eliminando las barreras que impiden la plena inclusión y participación de las mismas y en igualdad de condiciones en la sociedad.

En relación a lo anterior, de acuerdo a Cayo "Los distintos ordenamientos jurídicos renuncian implícitamente a una protección completa contra la discriminación y la no accesibilidad de las personas con discapacidad, al asumir que habrá esferas en que esa garantía no se producirá en todo momento y para todas las situaciones. Esto es así porque los ajustes, que ya son un dispositivo de protección de segundo grado, despliegan sus efectos cuando fracasa el dispositivo de accesibilidad universal y su presupuesto el diseño para todas las personas ${ }^{\prime \prime}$.

Los ajustes razonables procederán, sin embargo, sólo en el evento en que la conducta lo amerite por el nivel de desigualdad de la misma o el desvalor del acto discriminatorio aplicado al caso y finalmente cuando éstas sean razonables. La razonabilidad del ajuste restringe el número de éstos e imposibilita la realización de la medida cuando posee una carga excesiva o indebida o lleva implícita una desproporción tal en comparación al ajuste que finalmente no constituyen un deber y por tanto no son exigibles, dejando de ser su realización obligatoria, como se analizará más adelante ${ }^{10}$.

\section{El origen de los ajustes razonables}

La noción jurídica del acomodo o ajuste razonable nace en Estados Unidos y Canadá, a mediados de la década de los años setenta, desarrollándose progresivamente hasta nuestros días, extendiéndose a diversos países del mundo como una orientación jurídica útil para abordar la gestión de la diversidad religiosa y las normas antidiscriminatorias como corolario del derecho a la igualdad y no discriminación y en cumplimiento del principio de igualdad material, evitando la discriminación indirecta.

Los sujetos a los cuales se les aplicó esta técnica, desde el comienzo de su aplicación hasta su codificación, fueron principalmente las confesiones religiosas y los grupos vulnerables de población (grupos minoritarios cuyas características físicas, psíquicas o modos de vida escapaban a la generalidad de las personas a quienes las políticas se destinaban), quienes se veían afectados por las mismas ${ }^{11}$.

Su fundamento filosófico radica en el hecho de que corresponde a un medio adecuado para lograr un pluralismo integrador y cohesión social en sociedades

9 CAYO (2012), p. 166.

10 Se analiza con mayor detenimiento la carga excesiva en el título $\mathrm{N}^{\circ} 6$ del presente artículo.

11 Woehrling (1998), pp. 328-329. 
democráticas interculturales con un sólido Estado de Derecho entre personas con culturas diversas ${ }^{12}$, como son los casos de Estados Unidos y Canadá.

Por su parte, en el glosario del informe Bouchard-Taylor de Canadá, se define como un acuerdo que se enmarca en el ámbito jurídico a nivel jurisprudencial, que busca una relajación de la aplicación de una norma o de un estatuto en favor de una persona o de un grupo de personas en peligro de discriminación por uno de los motivos previstos en la Carta ${ }^{13}$.

Se busca que la adecuación se realice de forma eficaz y práctica con el objeto de acomodarse a las situaciones, intentando alcanzar una igualdad material para el sujeto afectado. Ésta debe, sin embargo, realizarse hasta el límite que no signifique una carga desproporcionada para el ente que debe efectuar la intervención, aplicando ciertos criterios para su determinación, entre los cuales se encuentran el de los costos-beneficios o de justicia-equidad, como se analizará más adelante.

Es así como, en Estados Unidos, nace aplicada a la diversidad cultural y religiosa a través de la enmienda del título VII del Civil Rights Act del año 1964 ${ }^{14}$; sin embargo, es a través de la aprobación de la Equal Employment Opportunity Act de 1972 (USA), que con la finalidad de combatir la discriminación en el mercado de trabajo se comienza a aplicar en forma recurrente en los fallos de los tribunales de justicia.

La técnica, si bien se utilizó originariamente en el campo de la discriminación religiosa, exigiendo que el empleador probara que no podía adaptarse razonablemente a las prácticas religiosas de sus empleados sin sufrir una carga indebida, con posterioridad se extendió a otros ámbitos ${ }^{15}$, entre ellos a la discapacidad. Lo anterior una vez aprobada la Americans with Disabilities Act en

12 Elósotegui (2014), p. 77.

13 Informe de la Comisión de Consulta sobre las Prácticas de Ajustes Razonables relativas a las Diferencias Culturales. Comúnmente conocida como la "Comisión Bouchard Taylor" (nombre de sus copresidentes). Fue creada el 8 de febrero de 2007 por Jean Charest, Primer Ministro de Quebec, para examinar las cuestiones ligadas a los ajustes razonables consentidos sobre las bases culturales y religiosas en Quebec. La Comisión estuvo dirigida por el filósofo Charles Taylor y el sociólogo Gérard Bouchard. Su informe final fue entregado en forma pública el 22 de mayo de 2008. La Comisión cerró su oficina el 18 de junio de 2008. En idioma inglés la cita originalmente expresa: "An arrangement that falls under the legal sphere, more specifically case law aimed at relaxing the application of a norm or a statute in favor of an individual or a group of people threatened with discrimination for one of the reasons specified in the Chart". Disponible en: https://www.mce.gouv.qc.ca/publications/CCPARDC/ rapport-final-integral-en.pdf, p. 289.

14 USA National Archives. Disponible en: http://www.archives.gov/education/lessons/civil-rights-act/.

15 De Campos (2011), pp. 92-93. 
1990, produciéndose en esa época intensos debates en cuanto a su extensión, tanto en la doctrina como en la jurisprudencia (USA) ${ }^{16}$.

Para determinar si una carga era desproporcionada en las situaciones anteriormente indicadas, se tenían en cuenta, entre otras cosas: los costos de la medida, los efectos discriminatorios que podría suponer su no adopción y la estructura y características de la persona, entidad u organización que había de ponerla en práctica, Ilevando a cabo el ajuste.

En Canadá, hace su aparición en el cuadro de las leyes y cartas conocidas como "cuasiconstitucionales", que garantizaban el derecho a la igualdad y prohibían en consecuencia las prácticas discriminatorias. La emergencia de la existencia de un método de acomodo a situaciones particulares fue el producto de una extensión cualitativa y significativa de la noción de discriminación, consagrada fundamentalmente en la Carta Canadiense de Derechos y Libertades (artículo 15) ${ }^{17}$ y en la Carta de Derechos y Libertades de Quebec (artículo 10) ${ }^{18}$. Una vez consagrada por la jurisprudencia, la técnica fue aplicada a la solución de cualquier acto discriminatorio, extendiéndose a otros actores y grupos considerados como "vulnerables"19. En los fallos se determinó la existencia de una obligación en los casos particulares de buscar soluciones porque, en caso contrario, se produciría una discriminación indirecta en el ejercicio de un derecho fundamental ${ }^{20}$.

Desde el punto de vista de la libertad religiosa, y enmarcada en el ámbito judicial, la sentencia "Petitioner's (Orthodox Jewsh) v. City of Outremont and Mouvement Laïque Québécois, Province of Quebec, district of Montreal. Superior Court", del año 200121, revela en forma ejemplar la aplicación de la técnica de los ajustes razonables por parte del juez canadiense en materia religiosa ${ }^{22}$.

En el caso particular la población de origen judía jasidista de Outremont construyó durante el período del Sabbat una estructura de hilos (semejantes a los hilos de pesca) con la intención de conectar los tejados de sus casas,

16 De Campos (2011), pp. 92-93.

17 Carta Canadiense de Derechos y Libertades. Disponible en: http://laws-lois.justice.gc.ca/fra/const/ page-15.html.

18 Carta de Derechos y Libertades de Quebec.

19 Véase De Campos (2011).

20 Informe de la Comisión de Consulta sobre las Prácticas de Ajustes Razonables relativas a las Diferencias Culturales, p. 39.

21 Petitioner's (Orthodox Jewsh) v. City of Outremont and Mouvement Laïque Québécois, Province of Quebec, district of Montreal. Superior Court. Canada. No 500-05- 060659-008, june 21 2001.

22 Véase Seglers (2013). 
provocando la protesta del Movimiento Laico de Quebec (Mouvement Laïque Québecoise) ante la municipalidad, señalando que el trenzado generaba una modificación de las calles, que perdían su neutralidad al pasar a formar parte de un espacio simbólico-religioso, afectando así a los vecinos no judíos en un ámbito, en definitiva, público.

A pesar de los fundamentos de la acción anterior, el Tribunal Superior de la Provincia de Québec resolvió en favor de la comunidad judía, disponiendo, entre otros razonamientos, que al ponderar la libertad religiosa con el interés público que pretendían defender los recurrentes, la primera prevalecía sobre el segundo en este caso concreto. La sentencia dispuso que "... la política multicultural exige que los operadores jurídicos canadienses procuren, cuando se trata de derechos fundamentales como el de la libertad religiosa, el 'acomodo razonable'".

Como el anterior caso, y enmarcados en diversas materias relativas a discriminación por concepto de raza y religión, se sucedieron sentencias en donde los jueces aplicaron la técnica de los ajustes o acomodo razonable hasta nuestros días, incluido en materia de discapacidad.

A nivel europeo, por su parte, tanto el Tribunal de Justicia de la Unión Europea como el Tribunal Europeo de Derechos Humanos han dictado sentencias recurriendo a esta técnica jurídica, como se analizará.

\section{Los ajustes razonables en el derecho de las personas en situación de discapacidad}

\subsection{Concepto}

Según la CPCD/ONU, por ajustes razonables "... se entenderán las modificaciones y adaptaciones necesarias y adecuadas que no impongan una carga desproporcionada o indebida, cuando se requieran en un caso particular, para garantizar a las personas con discapacidad el goce o ejercicio, en igualdad de condiciones con las demás, de todos los derechos humanos y libertades fundamentales"23.

De acuerdo al concepto anterior, constituyen un mecanismo de garantía del derecho de la igualdad de las personas en situación de discapacidad cuando se mantiene una situación concreta injusta. En este contexto tiene por objetivo dotar de contenido y preservar el derecho de la persona en situaciones particulares. Concretamente nace una obligación de actuar por parte de la persona que tiene la obligación de realizar el ajuste.

23 Convención sobre los Derechos de las Personas con Discapacidad (2006, "Artículo 2 Definiciones"; también en Tribunal de Justicia de la Unión Europea (TJUE), caso "Ring \& Skouboe Werge, 2013", y en otras sentencias posteriores a nivel europeo, se ratifica dicho concepto. 
Según Cayo el ajuste razonable corresponde a una"(...) conducta positiva de actuación del sujeto obligado por norma jurídica consistente en realizar modificaciones y adaptaciones adecuadas del entorno, entendido en un sentido lato, a las necesidades específicas de las personas con discapacidad en todas las situaciones particulares que éstas puedan encontrarse a fin de permitir en esos casos el acceso o el ejercicio de sus derechos y su participación comunitaria en plenitud, siempre que dicho deber no suponga una carga indebida, interpretada con arreglo a los criterios legales, para la persona obligada y no alcancen a la situación particular las obligaciones genéricas de igualdad, no discriminación y accesibilidad universal'24.

En este sentido, el mecanismo opera cuando existe una situación contraria al principio de igualdad en el caso concreto, habiendo por tanto fallado el sistema jurídico de derechos, por el hecho de que no ha sido capaz de regular todas las situaciones en que una PesD puede hallarse en su interacción con el entorno que la rodea y con la mayor intensidad de protección y aseguramiento de derechos que debería esperarse del mismo.

Esta técnica posee un fuerte contenido de justicia, pues tiene por objeto intentar hacer prevalecer dicha finalidad y valor cuando no se ha extendido jurídicamente a todos los ámbitos posibles, por lo que los ajustes razonables se entienden como una garantía al derecho a la igualdad, llevando la falta de concretización del mismo a generar una discriminación para el caso particular.

Ejemplo de lo anterior es posible advertirlo en el caso "Chacón Navas" en lo que respecta a los ajustes razonables en el mundo del trabajo. En este caso, el Tribunal de Justicia de la Unión Europea (en adelante TJUE) dispuso que la Directiva 2000/78/CE del Consejo, de 27 de noviembre de 2000, relativa al establecimiento de un marco general para la igualdad de trato en el empleo y la ocupación ${ }^{26}$, en su artículo 5, entrega directrices respecto de la forma en

24 CAYO (2012), p. 166.

25 Tribunal de Justicia de la Unión Europea. Sonia Chacón Navas v Eurest Colectividades SA, de 11 de julio de 2006. El caso se refiere a una ciudadana española, Sonia Chacón Navas, que fue declarada por su empleadora (en octubre de 2003) en baja laboral por enfermedad. En mayo de 2004, se le notificó por parte de su empleadora su despido. Chacón Navas presentó una demanda ante un tribunal español con el objeto que el despido fuera declarado nulo y fuera readmitida a su trabajo fundada en el hecho de que se había violado, por parte el empleador, de la Directiva 2000/78/CE del Consejo, de 27 de noviembre de 2000, relativa al establecimiento de un marco general para la igualdad de trato en el empleo y la ocupación fundado en el hecho de que, en el artículo 1, dentro de los objetivos de la misma se encontraba establecer un marco general para luchar contra la discriminación por motivos de discapacidad en el ámbito del empleo y la ocupación, con el fin de que los Estados miembros apliquen el principio de igualdad de trato.

26 Directiva 2000/78/CE del Consejo, de 27 de noviembre de 2000, relativa al establecimiento de un marco general para la igualdad de trato en el empleo y la ocupación. 
que debía entenderse el concepto en la aplicación práctica referida al mundo laboral, disponiendo: "... que los empresarios tomarán las medidas adecuadas, en función de las necesidades de cada situación concreta, para permitir a las personas con discapacidades acceder al empleo, tomar parte en el mismo o progresar profesionalmente, o para que se les ofrezca formación... ".

De lo anterior se colige la no existencia de ningún límite ni forma específica para la realización de ajustes, el que puede comprender cualquier tipo de actos. La sentencia dispone, asimismo, que el despido de un trabajador con discapacidad sería injustificado cuando el empleador no hubiere realizado los ajustes razonables necesarios para que éste pudiere trabajar en las mismas condiciones que los demás trabajadores que no poseen discapacidad ${ }^{27}$. El Tribunal dispuso asimismo como límite a los ajustes razonables "la carga excesiva", sin entregar un concepto de la misma.

\subsection{Elementos constitutivos}

En lo indicado con anterioridad se pueden detectar los siguientes elementos constitutivos del ajuste:

- La existencia de un acto u omisión proveniente de una norma jurídica, una política o un procedimiento, aplicado a la generalidad de la población. (los sujetos pasivos receptores del acto son la sociedad en general o un conjunto de personas que se encuentran en igualdad de condiciones);

- El acto, en su aplicación general, no es contrario al principio de igualdad y posee criterios de razonabilidad;

- El acto se vuelve contrario al principio de igualdad y resulta discriminatorio al ser aplicado a una situación específica, a un caso concreto;

- La existencia de un acto de autoridad que determina que la acción aplicada al caso concreto en particular resulta discriminatoria, normalmente se manifiesta a través de los fallos de los tribunales de justicia en procedimientos contenciosos;

- La realización de una conducta positiva de actuación de transformación del entorno dirigida a adaptar y hacer corresponder éste a la situación específica de las PesD, en todas las situaciones concretas en que éstas puedan hallarse, con el objeto de subsanar el acto discriminatorio, proporcionándoles una solución. Concretamente acomodando la aplicación de una norma, ley o política a favor de una persona o grupos de personas víctimas o amenazadas por discriminación;

- El ajuste realizado debe servir para remover efectivamente la barrera que impide la plena inclusión y participación de las PesD en igualdad de condiciones con las demás personas en la sociedad.

27 Tribunal de Justicia de la Unión Europea. Sonia Chacón Navas v Eurest Colectividades SA, 2006. C. $45^{\circ}$ y $50^{\circ}$. 
- El ajuste no debe producir una carga desproporcionada para el individuo que deba realizar la acción en consideración a las posibilidades que éste posee para su realización, tomando en cuenta los beneficios tanto individuales (para la PesD) como generales (para la comunidad) que el acto genere;

- La finalidad del acto corresponde a la inclusión de las PesD en igualdad de condiciones a la sociedad, debiendo poseer, por tanto, los elementos que posibiliten alcanzar el cumplimiento de dicho objetivo.

Otro punto discutido se encuentra referido al sujeto receptor del ajuste razonable: ¿debe ser siempre una PesD o puede ser alguna otra persona relacionada con ésta?: Dicho de otro modo ¿el sujeto receptor del acto discriminatorio debe ser la propia PesD o pueden ser otras personas relacionadas o ligadas con ésta?

La sentencia del caso Coleman del Tribunal de Justicia de la Unión Europea ${ }^{28}$ es ilustrativa a este respecto; en ella el Employment Tribunal, London South de Reino Unido, presentó una consulta prejudicial solicitando aclarar ciertos aspectos relativos a la aplicación de la Directiva 2007/78/CE - Igualdad de trato en el empleo y la ocupación ${ }^{29}$, relacionados con la discriminación directa por motivo de discapacidad; lo anterior ante la existencia del despido de un trabajador que no es una persona con discapacidad, pero cuyo hijo sí lo era ${ }^{30}$.

EI TJUE resolvió que la directiva no debe interpretarse de manera restrictiva, en el sentido de que prohíbe únicamente las discriminaciones directas por motivo de discapacidad que afecten exclusivamente a las propias personas con discapacidad, determinando que la citada directiva, al mencionar la Carta Comunitaria de los Derechos Sociales Fundamentales de los Trabajadores, remite tanto al combate general contra toda forma de discriminación como a la necesidad de adoptar medidas adecuadas para la integración social y económica de las personas con discapacidad.

Por lo anterior, los actos de discriminación y acoso en contra de un trabajador poseerán esta connotación si ellos son derivados del trato desfavorable del que es víctima dicho trabajador estando motivados por la discapacidad de un hijo suyo, a quien el trabajador prodiga la mayor parte de los cuidados que su estado requiere.

28 Tribunal de Justicia de la Unión Europea. S. Coleman v. Attridge Law and Steve Law, 2008.

29 Directiva 2007/78/CE - Igualdad de trato en el empleo y la ocupación. Artículos 1 y 2, apartados 1, 2, letra a), y 3, así como artículo 3, apartado 1, letra c).

30 El hijo de la señora Sharon Coleman nació con una rara condición que afecta su respiración, poseyendo además una discapacidad auditiva. La señora Coleman presentó una demanda alegando que se vio obligada a dimitir de su puesto de trabajo como secretaria legal después, según ella, del acoso de sus empleadores para renunciar al mismo y luego que se le denegó la aceptación de la realización de trabajo flexible, el que sí fue concedido a otros empleados sin que tuvieran hijos en situación de discapacidad. 
La sentencia determinó que los empleadores poseen la obligación no sólo de entregar facilidades, efectuando las adecuaciones o ajustes necesarios para los trabajadores con discapacidad, sino también a aquellos que, no siéndolo, posean el cuidado de una persona con discapacidad ${ }^{31}$. De lo anterior se concluye que los ajustes deben ser considerados en el contexto social en que la PesD se desarrolle y al interactuar tanto con la sociedad como con otras personas, entre ellas prestando especial atención a los apoyos que ésta reciba.

\section{Los ajustes razonables en la Convención de Naciones Unidas sobre los Derechos de las Personas con Discapacidad (CPCD)}

El artículo 2 de la Convención consagra la noción de ajustes razonables, en el capítulo dedicado a las definiciones, disponiendo que: "Por 'ajustes razonables' se entenderán las modificaciones y adaptaciones necesarias y adecuadas que no impongan una carga desproporcionada o indebida, cuando se requieran en un caso particular, para garantizar a las personas con discapacidad el goce o ejercicio, en igualdad de condiciones con las demás, de todos los derechos humanos y libertades fundamentales ${ }^{\prime 32}$. Del análisis de la disposición se pueden determinar las siguientes características:

El concepto ha sido redactado en términos amplios, pudiendo comprenderse las más variadas situaciones y actos;

Para lograr un ajuste razonable se deben realizar modificaciones y adaptaciones, sin determinarse las acciones precisas a realizar ni tampoco en qué ámbitos, por lo que su redacción se ha dejado abierta para que las autoridades o las personas encargadas de realizar el o los ajuste(s) puedan elegir aquella(s) práctica(s) que mejor se adapte(n) para el cumplimiento de la finalidad, en consideración a las particulares características del sujeto receptor o beneficiario del ajuste y su entorno, del medio o procedimiento que se debe adaptar y de las características culturales y nivel de desarrollo de cada país o sociedad;

Las modificaciones o adaptaciones deben ser "necesarias y adecuadas", esto es, deben cumplir con el objetivo de ajustar la situación existente a objeto de que las PesD puedan incluirse en igualdad de condiciones a la sociedad, eliminándose la barrera existente hasta este momento;

31 Tribunal de Justicia de la Unión Europea. S. Coleman v. Attridge Law and Steve Law, C-303/06, 2008. El tribunal reconoce los ajustes razonables concernientes al mundo del trabajo como: "[...] medidas de adaptación a las necesidades de las personas con discapacidad en el lugar de trabajo y para acondicionar el lugar de trabajo en función de la discapacidad de esas personas. Así pues, la finalidad específica de tales medidas es hacer posible y facilitar la inserción de las personas con discapacidad en el mundo del trabajo [...]". Considerando $\mathrm{N}^{\circ} 42$ del fallo.

32 Convención de Naciones Unidas sobre los Derechos de las Personas con Discapacidad, artículo $2^{\circ}$. 
El límite consagrado en la Convención para la realización del ajuste es la "carga indebida" para quien deba efectuarlo, sin determinar qué se entiende por ésta;

El ajuste razonable se debe aplicar a un caso particular, a una situación específica, en virtud de la cual la norma, no habiendo sido concebida con carácter discriminatorio, adquiere este carácter al ser aplicada al caso concreto;

El objetivo de la realización de los ajustes razonables es garantizar el pleno goce y disfrute de los derechos humanos de las PesD en igualdad de condiciones con las demás personas.

De un análisis a contrariu sensu de la norma se colige que la denegación de realizar ajustes razonables constituye una forma de discriminación por motivos de discapacidad.

Refuerza esta última característica del concepto antes indicado el otro artículo de la Convención, que se refiere a los ajustes razonables, el artículo 5, que dispone "A fin de promover la igualdad y eliminar la discriminación, los Estados Partes adoptarán todas las medidas pertinentes para asegurar la realización de ajustes razonables" ${ }^{\prime 33}$.

La sentencia sobre la entrega de beca de estudios de la Audiencia Nacional de España ${ }^{34}$ es ilustrativa respecto de la determinación del ajuste en conformidad al concepto contenido en la CPCD. El tribunal, aplicando directamente la Convención como fundamento del fallo, resolvió que a una PesD que presenta migrañas recurrentes e intensas y somnolencia prolongada no podía rechazársele el otorgamiento de una beca de estudio por no reunir los requisitos académicos necesarios existentes en la convocatoria, por el hecho de que su condición lo sitúa en desigualdad de condiciones frente a otros solicitantes sin discapacidad (que pueden seguir un régimen de estudios constante y regular) y que en el caso es lícito acudir a los ajustes razonables para eximirle del cumplimiento estricto de los requisitos académicos exigidos.

El tribunal aplicó como fundamento para dejar sin efecto el acto administrativo del Ministerio de Educación de España, que denegó el otorgamiento de la beca a dicha persona, la técnica de los ajustes razonables y consecuentemente la casa de estudios debió adaptar los procedimientos en cumplimiento de la sentencia.

33 Convención de Naciones Unidas sobre los Derechos de las Personas con Discapacidad, artículo $5^{\circ}$.

34 Audiencia Nacional. Jurisdicción Contencioso-Administrativa. Sentencia de 2 de noviembre de 2009; Número de procedimiento 160/2007. Jurisdicción Contencioso-Administrativa. Promovido D. Leoncio, representado por la Procuradora $D^{a}$. Virginia Rosa Lobo Ruíz y asistido por la Letrada $\mathrm{D}^{\mathrm{a}}$. Antonia Mateo Moreno, contra la Administración General del Estado (Ministerio de Educación y Ciencia), representada y asistida por el Abogado del Estado, sobre BECA. 
Dentro de las consideraciones del tribunal para aplicar los ajustes razonables al caso concreto consideró que se cumplían todos los supuestos para su aplicación, entre ellos la existencia de una situación de discapacidad, que en el caso particular por sus efectos origina una desigualdad indeseable aun cuando la regulación administrativa es idéntica para todos los supuestos de hecho; y la existencia de una desigualdad por razón de discapacidad, situación objetivamente desventajosa para la persona, por las consecuencias de la concreta discapacidad, lo que hacía necesario modificar las condiciones generales aplicables para introducir una adaptación adecuada que permita al sujeto el goce de sus derechos.

\section{La razonabilidad del ajuste y su límite}

La razonabilidad del ajuste y su límite debe ser determinada ante la existencia de casos concretos, sea que los sujetos vulnerados por la acción constituyan personas individuales o grupos específicos, quedando bajo criterios de ponderación por parte de las autoridades judiciales y públicas competentes en la modificación de políticas y procedimientos, la acción mayormente eficaz para cumplir con este fin. En este sentido, ella debe tener en cuenta elementos conectados con la eficiencia y economía en el uso de los recursos, conjuntamente con criterios de justicia, equidad y no discriminación. Existe una obligación jurídica de buscar soluciones, pues en caso contrario se producirá una discriminación indirecta en el ejercicio de un derecho fundamental.

\subsection{La carga excesiva o desproporcionada}

De acuerdo a lo indicado precedentemente, no todos los ajustes pueden ser realizados, sino sólo aquellos que poseen el carácter de "razonables". La determinación de lo que se entiende por "razonable" es compleja. Tanto la doctrina como la jurisprudencia han intentado determinar y precisar el límite del ajuste, el cual de acuerdo a la CPCD/ONU correspondería a la "carga excesiva" por parte del sujeto obligado al mismo.

Se ha entendido que este límite responde a criterios de justicia, fundados en el principio de igualdad, en donde el sujeto obligado a efectuar la acción deberá llevarla a cabo hasta un límite que no le produzca un perjuicio para él, sea económico o de cualquier otra diversa índole. También se considerará una carga excesiva si el ajuste es imposible de cumplir para el sujeto ejecutor o pasa a tener un efecto discriminatorio para otros sujetos posibles receptores colaterales del mismo.

Por lo anterior, el ajuste razonable conlleva un criterio de justicia no sólo para el sujeto pasivo de la conducta o el beneficiario de la misma, sino también 
para el sujeto activo o el obligado a la misma. Según Cayo "(...) no todas esas eventuales adaptaciones terminan siendo jurídicamente obligatorias, por más justas materialmente que puedan parecer, sino únicamente aquellas que sean razonables. El deber de realizar ajustes cesa en el momento en que los mismos no sean razonables con arreglo a una serie de criterios, que de ordinario la propia regulación concreta o meramente enuncia, que habrá que aplicar al caso particular suscitado"135.

Aceptando que cabe limitar la obligación de realizar ajustes a sólo aquellos que sean razonables, se vuelve del todo necesario determinar el contenido del concepto. En el Derecho comparado, aquellos países que poseen normas en sus ordenamientos jurídicos sobre la materia no precisan el alcance de los ajustes razonables ni de la carga excesiva, siendo sólo enunciados generales que imponen una obligación positiva de realizar ajustes indicando que su límite corresponde a la carga excesiva. Misma situación se encuentra en la CPCD/ONU. Además, cada situación específica en que se aplica el ajuste presenta sus propias particularidades, por lo que los criterios de determinación del mismo deben basarse en elementos comparativos de situaciones con características similares.

Lo anterior nos plantea múltiples interrogantes, entre ellas: ¿quién o quiénes y hasta dónde han de asumir responsabilidades en la realización de los ajustes?; ¿qué criterios deben tenerse en cuenta en la determinación de los mismos?; ¡ ien qué casos proceden y bajo qué circunstancias?; ¿cuál es la responsabilidad del Estado y de la sociedad en la realización de los mismos?

No existen respuestas generales a las interrogantes anteriores en los textos jurídicos existentes, por lo que se vuelve del todo necesario analizar la jurisprudencia, que nos permite ir acercándonos a algunos principios comunes aplicables en consideración a cada caso concreto y a las especiales características de los ordenamientos jurídicos y de las sociedades donde éstos deban realizarse.

De acuerdo a la doctrina y la jurisprudencia analizada, los siguientes factores copulativos son necesarios tener presentes para la determinación del límite del ajuste:

La situación de discapacidad de la persona, la que debe determinarse respecto de la interacción de la misma con el medio donde se desenvuelve;

La magnitud de la transgresión del derecho;

El desvalor que conlleva la transgresión del derecho y el valor que implica para la sociedad su reparación;

Las características del acto que restablecerá el derecho vulnerado en el caso particular, $y$

35 CAYO (2012), p. 166. 
Las características particulares del sujeto que debe realizar el ajuste en consideración al derecho transgredido.

Estos factores generales interrelacionados entre sí y ponderados por la autoridad en un momento dado posibilitarían determinar la existencia de un ajuste razonable o una carga indebida, sin perjuicio de la rápida evolución del Derecho, sobre todo de los derechos humanos, con el consecuente desarrollo de otras posibles causales que han de tenerse en consideración.

Así, con el objeto de entender, de mejor manera, a modo ilustrativo, en los casos acumulados C-335/11 y C-337/11 Ring y Skouboe Werge 2013 ${ }^{36}$, referidos a la no discriminación en el empleo, se observa cómo el juez resolvió la aplicación de la técnica de los ajustes razonables y la extensión de los mismos. En él un sindicato de trabajadores, HK Danmark, interpuso una demanda de indemnización en nombre de dos de sus trabajadoras en situación de discapacidad $^{37}$, despedidas a través de un procedimiento de preaviso abreviado por sus respectivos empleadores.

EI TJUE recordó que, conforme a la Directiva 2007/78/CE - Igualdad de trato en el empleo y la ocupación, los empresarios han de adoptar medidas de ajuste adecuadas y razonables para permitir a las personas con discapacidades acceder al empleo, tomar parte en él o progresar profesionalmente, por lo que la reducción del tiempo de trabajo, aunque no estuviera comprendida en el concepto de "pautas de [tiempo de] trabajo", explícitamente evocado por la directiva, puede considerarse como una medida de ajuste apropiada en los casos en los que esa reducción permita al trabajador continuar ejerciendo su empleo. No obstante, incumbe al juez nacional apreciar si, en los casos de que se trata, la reducción del tiempo de trabajo como medida de ajuste supone una carga excesiva para los empleadores.

En el caso concreto, las medidas de reducción de tiempo de trabajo se consideraron como un ajuste razonable adecuado, salvo que el empleador pudiese

36 Tribunal de Justicia de la Unión Europea. C-335/11 y C-337/11 Ring y Skouboe Werge, 2013, Sala Segunda, del 11 de abril de 2013. El sindicato afirmó que las dos trabajadoras presentaban una discapacidad y que sus empleadores, en vista de lo anterior, tenían que haberles propuesto una reducción del tiempo de trabajo y no haberlas despedido. Sostuvo igualmente que la disposición nacional relativa al preaviso abreviado no puede aplicarse en el caso de estas dos trabajadoras, ya que sus bajas por enfermedad eran consecuencia de sus discapacidades. Ante la situación anterior, el "Sø- og Handelsretten" (Tribunal Marítimo y Mercantil, de Dinamarca), que conoció de ambos asuntos, presentó ante el Tribunal de Justicia de la Unión Europea una cuestión prejudicial para que precisara el concepto de discapacidad. La acción también tenía por objeto determinar si la reducción del tiempo de trabajo podía considerarse como una medida de ajuste razonable y si la ley danesa relativa al preaviso abreviado para el despido era contraria al Derecho de la Unión, todo lo anterior en conformidad con la Directiva 2007/78/CE - Igualdad de trato en el empleo y la ocupación.

37 Señoras Jette Ring y Lone Skouboe Werge. 
probar que le provocaban una carga excesiva, disponiendo asimismo que la realización de los ajustes necesarios no sólo se refiere a medidas materiales, sino también organizativas, y para determinar el límite del ajuste se deben tener en cuenta, particularmente, los costos financieros y de otra índole, como el tamaño, los recursos financieros y el volumen de negocios total de la organización o empresa y la disponibilidad de fondos públicos o de otro tipo de ayuda ${ }^{38}$.

\subsection{Criterios jurisprudenciales en la determinación del ajuste razonable}

De acuerdo a lo anteriormente analizado, se puede inferir que la determinación del ajuste razonable en el caso concreto es compleja, poseyendo el límite de la carga excesiva establecido por la propia CPCD/ONU, la que dispone asimismo que la no realización del ajuste engendra una acto discriminatorio, por lo que su extensión deberá asegurar tanto el cumplimiento del principio de igualdad material hacia las PesD y no discriminación como evitar la producción de una carga excesiva para el sujeto activo del ajuste. Con el objetivo de poder establecer el límite entre el ajuste razonable y la carga indebida, es decir, el punto exacto donde el ajuste deja de ser razonable, se han ido desarrollando diversos criterios jurisprudenciales para su determinación, que se analizarán a continuación.

\section{a) Determinación de acuerdo a la teoría de los costos y beneficios}

En esta aproximación, la carga excesiva corresponde al gravamen indebido que recae sobre el sujeto obligado a efectuar el ajuste en conformidad a la capacidad económica y de recursos materiales que éste posea. Dos son los elementos esenciales que el juez toma en cuenta en la ponderación de la misma: por un lado, los beneficios para las personas en situación de discapacidad luego de la realización del ajuste, y, por otro, los recursos económicos que posee el sujeto que debe efectuar el mismo ${ }^{39}$.

En esta concepción el sujeto que requiere el ajuste (beneficiario del mismo) debe demostrar que éste es eficaz y proporcional a los costos para realizarlo, es decir, que el beneficio obtenido será mucho mayor a los costos que éste representan para la persona obligada a la realización del mismo. Mientras que el sujeto que posee el deber de acomodar, de realizar el ajuste, puede presentar dos excepciones: por un lado, que los costos son excesivos en relación a los

38 Conclusiones de la abogada general Sra. Julianne Kokott, presentadas el 6 de diciembre de 2012. Considerando $59^{\circ}$.

39 United States Court of Appeals. Vande Zande v. Wisconsin Dept of Admin. USA, 1995. 
beneficios obtenidos, y, por otro, la imposibilidad de llevarlos a cabo por su condición financiera ${ }^{40}$.

La teoría anterior, como criterio aplicable para la determinación de los ajustes razonables, ha recibido diversas críticas, entre ellas las que disponen que ésta no considera aspectos claves en el campo de la discriminación y la imposibilidad de medición de aspectos como la humillación, la desigualdad y la estigmatización que pueda sufrir la persona en situación de discapacidad para ponderar la justicia de la acción ${ }^{41}$. Por lo que, al momento de realizar el ejercicio de costos y beneficios en la determinación de un ajuste razonable, no sólo deben ser considerados aspectos de índole economicista.

Una segunda crítica se refiere a que, al momento de efectuar el ajuste, no se consideran aspectos como el beneficio social que puede significar su realización. Es así como el ajuste efectuado para uno o pocos individuos permite que éstos puedan participar y hacer parte de una colectividad, convirtiendo de esta manera a toda la sociedad en beneficiaria del mismo. Lo anterior tanto desde una medición de tipo económica (pues corresponden a una fuerza económica y social importante) como desde el punto de vista de una mirada de derechos humanos.

La puesta en práctica de esta teoría por parte de los jueces de los Estados Unidos se efectuó en materia laboral, a través de la aplicación del "Acta de los Estados Unidos sobre las Personas con Discapacidad"42 (en adelante ADA). Ésta mandata la realización de ajustes razonables en los ambientes de trabajo de las empresas a favor de trabajadores en situación de discapacidad, siendo las cortes de dicho país las que fueron creando criterios jurisprudenciales para su determinación ${ }^{43}$. En el ADA, los ajustes razonables en el mundo del trabajo pueden comprender dos situaciones fundamentales: los ajustes en las condiciones del lugar de trabajo y la alteración de la forma en que el trabajo es desarrollado por el trabajador.

En lo que respecta al lugar del trabajo, el límite establecido por el ADA se encuentra dado cuando se le presenta una dificultad significativa al empleador en la realización del gasto económico requerido por el ajuste. Dicha ponderación debe efectuarse tomando en cuenta, en su conjunto: los recursos totales financieros, tamaño y número de personas empleadas, los efectos del gasto de recursos, locación, estructura y funciones de la fuerza de trabajo, como asimismo el impacto general de la realización de los ajustes.

40 United States Court of Appeals. Vande Zande v. Wisconsin Dept of Admin. USA, 1995.

41 SusteIn (2007).

42 The Americans with Disabilities Act 1990. Disponible en: http://www.ada.gov/pubs/adastatute08.htm.

43 Ashley (2003). 
Siguiendo los criterios antes indicados por el ADA, los jueces norteamericanos Richard Posner y Guido Calabresi, en diferentes casos donde emitieron sus pronunciamientos jurídicos, fueron sentando precedentes importantes en la configuración de esta teoría, disponiendo que para la determinación del ajuste debe efectuarse un análisis costo-beneficio ${ }^{44}$, estimando las circunstancias financieras del empleador en el caso concreto ${ }^{45}$.

De acuerdo con Posner, la dificultad residía en definir lo que se entiende por "razonable". En el caso "USA, 1995, Vande Zande v. Wisconsin Dept of Admin.", para la parte demandante "razonable" correspondía al ajuste que era eficaz para el individuo, los costos no entraban en la definición de razonable, sino en la de carga indebida. Sin embargo, Posner disintió respecto de lo anterior, disponiendo que "razonable" debía ser interpretado como una adjetivación que debilita el ajuste, o sea, en el sentido en que la palabra se aplica en el Derecho Civil (por ejemplo, esfuerzo razonable, diligencia razonable), indicando un emprendimiento ordinario sin que signifique la realización del máximo posible o del máximo deseable.

La locución "carga indebida", que había sido interpretada por el juez de primera instancia como el gravamen indebido que recae sobre el empleador según su capacidad económica, en la lectura de Posner se debía interpretar como la suma de dos elementos: los beneficios para la persona en situación de discapacidad y los recursos del empleador.

En la concepción de Posner, el análisis de los costos entra en escena en un segundo momento, en el cual quien requiere el ajuste debe demostrar que éste es eficaz y proporcional a los costos. El sujeto que tiene el deber de acomodar puede presentar dos excusas: que los costos son excesivos en relación con los beneficios y la imposibilidad de afrontarlos debido a su condición financiera real ${ }^{46}$.

Las críticas con respecto a la teoría de los costos y beneficios, aun cuando entregan lineamientos para la determinación del ajuste, radican, como ya se indicó, fundamentalmente en el hecho de que existen beneficios incuantificables, como son los beneficios externos positivos que reviste para todos los trabajadores de una empresa o lugar de trabajo y de la sociedad en general que las PesD se incluyan en el mundo productivo en igualdad de condiciones que los demás. Si bien el ejemplo anterior se aplica al mundo del trabajo (donde existe la mayor cantidad de jurisprudencia), ésta es extensible a cualquier hecho

\footnotetext{
44 United States Court of Appeals. Vande Zande v. Wisconsin Dept of Admin., 1995; también en United States Court of Appeals, Borkowski v. Valley Cent. Sch Dist., 1995.

45 United States Court of Appeals. Vande Zande v. Wisconsin Dept of Admin., 1995; también en United States Court of Appeals, Borkowski v. Valley Cent. Sch Dist., 1995.

46 United States Court of Appeals. Vande Zande v. Wisconsin Dept of Admin., 1995.
} 
y ámbito social en que se requiera la aplicación de la técnica para alcanzar una igualdad material.

\section{b) Determinación de acuerdo a la jurisprudencia canadiense}

Desarrollada en Canadá, fundamentalmente en materia de empleo, a diferencia de la teoría de costos y beneficios, la determinación de la carga excesiva no comprende sólo contenido de índole económico, sino que incorpora otros aspectos. Según Bosset para la determinación de los ajustes se aplican los siguientes criterios $^{47}$ :

En primer lugar, la limitación o carga excesiva para el empleador, denominada "límites funcionales", que puede existir al menos en tres tipos de situaciones:

a) Los límites de los recursos financieros, el costo real del ajuste, las fuentes de financiamiento del mismo, si son de la propia empresa o externa, el tipo de empresa o de institución, el presupuesto de la misma, la coyuntura económica, entre otros;

b) Las trabas en la explotación de la empresa ${ }_{L}$ tomando en cuenta criterios como si se restringe excesivamente los fines de la institución (educativa, sanitaria de servicios públicos, etc.) o dificulta gravemente su funcionamiento porque suponga una desorganización funcional de los organismos, la no intercambiabilidad de los empleados, la adaptación de los espacios o de las instalaciones y equipo de trabajo, los efectos sobre la productividad, los efectos benéficos sobre los otros empleados, la duración de la medida, entre otros;

c) Por otro lado, los derechos de los otros empleados o los otros usuarios, comprendiendo los riesgos para la salud o la seguridad de los empleados, de los colegas o del público, el convenio colectivo, los conflictos de derechos, entre otros.

En segundo lugar, continúa Bosset, se encuentran los "límites sociales", correspondiendo a "límites formales marcados por el derecho", los que comprenden: el orden público y la seguridad, los valores democráticos y el bienestar en general (o los derechos y libertades de los demás) ${ }^{48}$.

Las cortes canadienses, a través de sus fallos, han resuelto que cada uno de estos criterios deben ser ponderados, entregándoseles mayor o menor importancia dependiendo de las situaciones concretas existentes en cada caso ${ }^{49}$.

En cuanto a los procedimientos para llegar a un ajuste razonable, las cortes han dispuesto que éste constituye un espacio dialógico en donde todos los

47 Citado por Elosótegui (2014), pp. 79-80.

48 Citado por Elosótegul (2014), pp. 79-80.

49 Supreme Court of Canada, 1990, Central Alberta Dairy Pool V. Alberta. 
implicados deben participar. De esta manera aquel que solicita el ajuste tiene el deber de explicar sus limitaciones y necesidades, y en lo posible señalar alternativas para su realización. Por su parte, el destinatario de la solicitud de ajuste debe ofrecer propuestas razonables, y, si realmente lo fueran, el demandante tiene el deber de facilitar y contribuir a su implementación ${ }^{50}$. Por lo anterior, la búsqueda del ajuste razonable se traduce en un proceso de diálogo multilateral, participativo e inclusivo.

\section{c) Determinación de acuerdo a la interpretación del Convenio Europeo de Derechos Humanos}

La Corte Europea de Derechos Humanos en materia de discapacidad ha venido aplicando la técnica de los ajustes razonables fundada en el concepto de discriminación indirecta, prohibiendo tratamientos diferenciados que resulten discriminatorios, lo anterior a través del conocido "test de proporcionalidad", que en casos de "discapacidad" ha incluido tanto límites sociales como funcionales de la persona, es decir, en concordancia con el enfoque social de derechos.

En la aplicación del test, la Corte se ha basado en los tres criterios esenciales que ella comprende: primero, el Estado debe demostrar en el caso de una norma en litigio que dicha medida persigue un fin legítimo; segundo, que existe una relación razonable de proporcionalidad entre los medios empleados y la finalidad buscada; $y$, tercero, que no existe otra medida que, logrando el mismo fin, dañe en menor medida el derecho individual, es decir, sea menos gravosa para el particular al que se limita el ejercicio de un derecho legítimo ${ }^{51}$.

La Corte se refirió directamente a la Convención de Naciones Unidas sobre los Derechos de las Personas con Discapacidad (CPCD/ONU) en la sentencia que resuelve el caso Glor v. Switzerland $\left(\mathrm{N}^{0} 13444 / 04\right)^{52}$. En él Sven Glor, ciudadano suizo, fue declarado, a pesar de su interés, no apto para el servicio militar por presentar diábetes. A pesar de ello, el señor Glor recibió la orden de pagar la cantidad de 477 euros establecida para quien no realizase el servicio

\footnotetext{
50 Supreme Court of Canada, Canadá Okanagan School District No 23 V. Renaud.

51 En relación al primer criterio el concepto indeterminado de "fin objetivo y legítimo" será interpretado por el juez y se concretará a la luz de las circunstancias concretas del caso, lo mismo es aplicable al segundo criterio: serán también los jueces quienes decidirán, utilizando los métodos habituales de argumentación jurídica, como el de proporcionalidad y ponderación, si existe una relación razonable de proporcionalidad entre los medios empleados y la finalidad buscada. En relación con el ejercer criterio, también como parte del concepto de proporcionalidad, el Tribunal examina si la restricción del derecho para ese ciudadano o la aplicación de esa norma general sin admitir excepciones le supone un sacrificio excesivo de su derecho.

52 European Court of Human Rights. Case of Glor v, Switzerland Solicitud No 13444/04 2009. En: http://hudoc.echr.coe.int/sites/fra/pages/search.aspx?i=001-92524\#\{“itemid":[“001-92524"]\}.
} 
militar. La Administración Federal de Hacienda recomendó un examen adicional para determinar si el recurrente tenía una "gran discapacidad", es decir, el $40 \%$ de grado requerido para no pagar dicha sanción. Varios informes médicos señalaron que el grado de discapacidad del señor Glor era menor; asimismo, el recurrente no podía realizar la prestación social sustitutoria reservada para objetores de conciencia.

Ante estos hechos, el Tribunal resolvió, aplicando el test de proporcionalidad, que existió violación del artículo 14 de la Convención Europea de Derechos Humanos dedicado a la prohibición por discriminación, señalando que dentro del concepto de "o cualquier otra situación" está incluida la discapacidad, y relacionándolo con el artículo 8 (respeto de la vida privada y familiar) de la misma Convención. Asimismo, la sentencia hizo referencia a la CPCD/ONU como marco jurídico de referencia.

Declaró además el Tribunal la restricción de la capacidad de los Estados para tratar de forma diferente a las personas en situación de discapacidad cuando, como es el caso, la realización de ajustes razonables puede eliminar dicha diferencia. El tribunal sugiere que a las personas en las circunstancias del señor Glor se les deberían ofrecer formas alternativas de realizar el servicio militar que requieran menor esfuerzo físico y compatibles con sus limitaciones, o la realización de la prestación social sustitutoria, aunque no sean objetores de conciencia.

Otros puntos destacables de la sentencia corresponden al tratamiento dado a la discriminación por motivo de discapacidad, donde el límite del grado no puede ser ya contemplado como un argumento básico, como también viene a señalar la CDPD, y la inclusión de la diabetes dentro del concepto de discapacidad.

El test de proporcionalidad se centró en determinar si el efecto de la norma (medida que prohibía la realización del servicio militar y pago de multa) era desproporcionado, lo que, en el caso, obligaba al Estado a adoptar una solución que flexibilizara la norma para evitar el impacto adverso en el señor Glor y sus ciudadanos en general, evitando la discriminación indirecta de la norma. Se concedió finalmente un tratamiento especial positivo favorable basándose en el principio de igualdad, realizándose una adaptación de la misma ${ }^{53}$.

\section{Conclusiones}

La Convención de Naciones Unidas sobre los Derechos de las Personas con Discapacidad, aparte de instaurar un nuevo paradigma, el social de derechos humanos, codificó la obligatoriedad de realizar ajustes o modificaciones cuando

53 Véase Greer (2000). 
una norma o una situación, sin ser en su origen discriminatoria o contraria al principio de igualdad, aplicada a un caso concreto en el cual el destinatario de la misma es una persona en situación de discapacidad, deviene injusta y discriminatoria y claramente representa una vulneración del principio de igualdad material o efectiva.

Ante esta situación nace la obligación para el sujeto que realiza o mantiene una acción u omisión vulneratoria de derechos de hacerla cesar, debiendo realizar una acción material hasta un límite que no le produzca un perjuicio para él, sea económico o de cualquier otra diversa índole, lo que se denomina como "carga excesiva". La determinación del ajuste es compleja, por el hecho de que ni las legislaciones internas de los países ni la propia CPCD/ONU entregan un concepto claro de lo que se entiende por ajustes razonables.

En relación a las características del ajuste se puede inferir que éste se aplica a un acto u omisión proveniente de una norma jurídica, una política o un procedimiento, aplicado a la generalidad de la población; acción u omisión que no es contrario al principio de igualdad y posee criterios de razonabilidad; el que se vuelve contrario al indicado principio al ser aplicado a una situación específica; luego debe existir un acto de autoridad que determina que la acción aplicada al caso concreto resulta discriminatoria; la realización de una conducta positiva de actuación de transformación del entorno dirigida a adaptar con el objeto de subsanar el acto discriminatorio, proporcionando una solución, y que el ajuste realizado debe servir para remover efectivamente la barrera que impide la plena inclusión de la PesD en la sociedad, sin producir una carga desproporcionada para el individuo que deba realizar la acción.

Las características antes identificadas del ajuste razonable y de la carga indebida provienen del análisis de sus conceptos jurídicos, como asimismo de las construcciones desarrolladas en las sentencias de los diversos tribunales en el derecho comparado.

Dentro de las construcciones jurisprudenciales cabe destacar la teoría de los costos y beneficios, en donde dos son los elementos esenciales que el juez toma en cuenta y debe ponderar al momento de determinar el ajuste, consistentes en los beneficios para las PesD luego de la realización del ajuste y los recursos económicos que posee el sujeto que debe efectuar el mismo. Dicha teoría es, sin embargo, objeto de críticas por el hecho de que los beneficios que se obtienen de la realización del ajuste van mucho más allá de aspectos económicos; criterios que sí son considerados, junto a otros, por la jurisprudencia de los tribunales canadienses. Por su parte, el Tribunal Europeo de Derechos Humanos utiliza el test de proporcionalidad para su determinación, aplicando directamente como fuente jurídica la CPCD/ONU.

El derecho de las personas en situación de discapacidad, en plena evolución, plantea un cúmulo de interrogantes en relación a la técnica jurídica de 
los ajustes razonables y su aplicación al caso concreto, por lo que habrá que seguir de cerca su construcción a través de la evolución jurisprudencial como forma de determinar los criterios para saber si un ajuste es considerado como razonable o sobrepasa el límite de éste, transformándose en una carga excesiva.

\section{Bibliografía CitADA}

Ashley Stein, Michael (2003): "The law and economics of disablity accomodations", en: Duke Law Journal (vol. 53:79), pp. 79-191.

Biel Portero, Israel (2009): "Los derechos de las personas con discapacidad en el marco jurídico internacional universal y europeo", en: Tesis Doctoral. Dirigida por el Dr. D. Jorge Cardona Llorens (Castellón, Universitat Jaume).

Cayo Pérez Bueno, Luis (2012): "La configuración jurídica de los ajustes razonables", en: Revista "2003-2012: 10 años de Legislación sobre no Discriminación de Personas con Discapacidad en España. Estudios en homenaje a Miguel Ángel Cabra de Luna". Comité Español de Representantes de Personas con Discapacidad (Cermi) ( $N^{\circ} 55$ ).

De Campos Velho Martel, Leticia (2011): "Ajuste razonable: Un nuevo concepto desde la óptica de una gramática constitucional inclusiva", en: Revista de Derechos Humanos, Sur. 2011 (vol. 8, № 14), pp. 88-115.

Elósotegui Itaxo, María (2014): "El concepto jurisprudencial de acomodamiento razonable. El Tribunal Supremo de Canadá y el Tribunal Europeo de Derechos Humanos ante la gestión de la diversidad cultural y religiosa en el espacio público", en: Anuario de Filosofía del Derecho AFD (XXX)(Universidad de Zaragoza), pp. 69-96.

Bosset, Pierre (2007): "Les Limites de l'accommodement raisonnable: le droit a-t-il tout dit?", en: Revue Etique Publique (vol. 9, № 1).

Greer, Steven (2000): 'La marge d'appreciation: Interpretation et pouvoir discrétionnaire dans le cadre de la Convention Européenne des droits de l'homme", en: Université de Bristol, Royaume-Uni. Dossiers sur les droits de l'homme ( No 17) (Editions du Conseil d'Europe).

Lawson, Anna (2008): Disability and Equality Law in Britain, The Role of Reasonable Adjustment, (Oregon, Oxford and Portland).

Oliver, Mike (1990): The Politics of Disablement (Basingstoke, Palgrave Mcmillan). PfelfFer, David (2002): "The Philosophical Foundations of Disability Studies", en: Center on Disability Studies University of Hawaii at Manoa. Disability Studies Quarterly. Spring 2002 (vol. 22, Nº 2).

QuinN, Gerard (2009): "Disability and Human Rights: a New Field in the United Nations",en: Krause, C. y Scheinin, M. (Eds.), International Protection of 
Human Rights: a Textbook (Turku/Abo, Finland, Abo Akademi University, Institute for Human Rights).

RamBAUD, Thierry (2013): Apuntes de la clase "L'Etat et les Religions" en el curso anual del Institut International des Droits de L'Homme (Stasbourg, Francia).

Seglerss, Alex (2013): Simbología religiosa y espacio público. Comentario a la sentencia canadiense Petitioner's (Orthodox Jewish) v. City of Outremont and Mouvement Laïque Québécoise (Navarra, Ediciones Universidad de Navarra).

Sunstein CAss, R. (2007): "Cost-Benefit Analysis Without Analyzing Costs of Benefits: Reasonable Accommodation, Balancing, and Stigmatic Harms", en: University of Chicago Law \& Economics, Olin Working Paper ( $\left.\mathrm{N}^{\circ} 325\right)$; University of Chicago, Public Law Working Paper ( $N^{\circ} 149$ ).

WoEHRLING, José (1998): "L'obligation d'accommodement raisonnable et I'adaptation de la société a la diversité religieuse", en: Revue de Droit de McGill (McGill Law Journal).

\section{JURISPRUDENCIA CITADA}

Audiencia Nacional de España, Jurisdicción Contencioso-Administrativa, Sentencia de 2 de noviembre de 2009; Número de procedimiento 160/2007. Corte de Apelaciones de Estados Unidos.

Vande Zande v. Wis Dept of Admin. (7th Cir. 1995).

Borkowski v. Valley Cent. Sch Dist., (2nd Cir. 1995).

Corte Europea de Derechos Humanos

Glor v, Switzerland. Solicitud No 13444/04, 2009.

Corte Superior de la Provincia de Quebec, Distrito de Montreal, Canadá

Petitioner's (Orthodox Jewsh) v. City of Outremont and Mouvement Laïque Québécois, Court No 500-05- 060659-008, june 21, 2001.

Corte Suprema de Canadá

Central Alberta Dairy Pool V. Alberta. 1990.

Okanagan School District No 23 V. Renaud. 1992.

Tribunal de Justicia de la Unión Europea

Sonia Chacón Navas v Eurest Colectividades SA2, 2006.

S. Coleman v. Attridge Law and Steve Law, 2008.

Ring and Skouboe-Werge-Disability, 2013. 